\title{
Pengaruh Pemberian Dekokta Kayu Bajakah Tampala (Spatholobus Littoralis Hassk) Terhadap Penurunan Udem Kaki Tikus Putih (Rattus Norvegicus) Jantan Yang Dinduksi Karagenin
}

\author{
Dahlia Andayani $^{1 *}$, Faridiniyati Hidayaturrohimah ${ }^{1}$ dan Khairil Pahmi ${ }^{1}$ \\ ${ }^{1}$ Jurusan Farmasi, Universitas Nahdlatul Wathan, Mataram, Indonesia \\ *Email : dahliaandayani6@gmail.com
}

\begin{abstract}
Abstrak : Udem merupakan suatu respon protektif normal terhadap luka jaringan yang disebabkan oleh trauma fisik, zat kimia, maupun zat mikrobiologi. Tumbuhan bajakah tampala (Spatholobus littoralis Hassk) yang mempunyai kandungan flavonoid diharapkan dapat dijadikan sebagai obat dalam pengobatan udem. Penelitian ini bertujuan mengetahui efek decocta kayu Bajakah pada volume udem kaki tikus yang diinduksi karagenin.
\end{abstract}

Penelitian ini menggunakan rancangan pre post test control group design. Hewan uji 24 ekor tikus jantan dibagi menjadi 4 (empat) kelompok, setiap kelompok terdiri dari 6 hewan uji, yakni kontrol negatif (CMC )kontrol positif (Natrium diklofenak )perlakuan 1 (dekokta kayu bajakah dosis 20g/100 ml selama 3 hari dan perlakuan 2 (dekokta kayu bajakah dosis $20 \mathrm{~g} / 100 \mathrm{ml}$ sekali sehari. . Semua perlakuan diberikan secar oral dan caragenin diberikan secara subcutan pada telapak kaki tikus. Volume udem diukur dengan alat pletismometer pada selang waktu tertentu.

Hasil penelitian menunjukkan AUC Volume udem kontrol negatif sebesar 0,10833, kontrol positif sebesar 0,02816, perlakuan 1 sebesar 0,03133, dan perlakuan 2 sebesar 0,04683. Persen daya anti inflamasi (\%DAI) yaitu kontrol positif 74,04\%, perlakuan $171,08 \%$, dan perlakuan $256,77 \%$. Nilai signikansi lebih kecil dari 0,05 menunjukkan ada pengaruh yang bermakna dari pemberian dekokta kayu bajakah terhadap penurunan Volume Udem tikus. hasil uji Mann-Whitney antara kontrol positif dengan perlakuan 1 menghasilkan signifikansi 0,394 $(>0,05)$ berarti tidak terdapat perbedaan secara bermakna atau dengan kata lain memiliki efek yang sama dengan natrium diklofenac.

Kata kunci: Dekokta kayu bajakah, Daya anti inflamasi, volume udem, AUC, Karagenin

\section{Pendahuluan}

Salah satu tanaman yang dapat dimanfaatkan sebagai bahan obat tradisional adalah tumbuhan bajakah, yang dalam bahasa Dayak artinya akar bukan suatu spesies tumbuhan-tertentu (Balitabang Kemenkes, 2019) Baru-baru ini bajakah menjadi pusat perhatian masyarakat karena dipercaya dapat menyembuhkan kanker payu darah (Bramasta,dan Sartika,. 2019). Menurut hasil penelitian yang dilakukan oleh tiga siswa SMA dari Kalimantan Tengah yang menyatakan bahwa ekstrak air bajakah dapat menyembuhkan kanker terhadap hewan uji mencit (Fitriya, 2019). Salah satu tumbuhan yang dimanfaatkan secara empiris sebagai obat oleh masyarakat di desa Garung adalah bajakah tampala (Spatholobus littoralis Hassk) (Saputera, 2019).

Berdasarkan uji pendahuluan secara kualitatif yang dilakukan oleh Anshari (2012) bajakah tampala mengandung fenolik, flavonoid, tanin dan saponin. Kandungan senyawa metabolit sekunder ini dapat mengobati berbagai penyakit degeneratif, seperti diabetes, kanker, tumor dan lain-lain. Flavonoid berfungsi sebagai antiinflamasi dengan cara menghambat enzim siklooksigenase dan lipooksigenase dapat memberikan harapan untuk pengobatan gejala peradangan dan alergi. Flavonoid adalah metabolit sekunder dari polifenol, ditemukan secara luas pada tanaman serta makanan dan memiliki berbagai efek bioaktif termasuk antivirus dan anti-inflamasi (Qinghu Wang, 2016)

Inflamasi merupakan suatu respon protektif normal terhadap luka jaringan yang disebabkan oleh trauma fisik, zat kimia yang merusak atau zatzat mikrobiologi. Inflamasi juga dapat diartikan sebagai usaha tubuh untuk mengaktivasi atau merusak organisme yang menyerang, menghilangkan zat iritan, dan mengatur perbaikan jaringan. Tanda-tanda inflamsi seperti kemerahan, bengkak, panas, nyeri, dan gangguan fungsi (Anonim, 2010).

Berdasarkan uraian di atas, Tumbuhan bajakah tampala (Spatholobus littoralis Hassk) yang mempunyai kandungan flavonoid diharapkan dapat dijadikan sebagai obat dalam pengobatan udem. Penelitian ini di maksud untuk memberi data ilmiah tentang efek dekokta kayu bajakah tampala terhadap penurunan udem pada tikus, kemampuan penurunan udem di tandai dengan turunnya volume 
udem pada hewan uji yaitu tikus. Sediaan dekokta dipilih untuk menyusuaikan dengan penggunaan masyarakat, sehigga diharapkan akan memberikan efek yang sama pada saat di lakukan pengujian terhadap hewan uji.

\section{Metode Penelitian}

Pembuatan dekokta kayu Bajakah

Sampel kayu bajakah tampala diproleh dari distributor online. Simplisia kayu Bajakah yang sudah dipotong potong diperkecil lagi ukurannya untuk memperluas permukaan kontak dengan air penyari. $100 \mathrm{ml}$ air digunakan untuk menyari 20 gram Bajakah, direbus hingga suhu 90 derajat celcius selama 30 menit. Setelah itu disaring dan diberikan kepada hewan uji secara per oral dengan sonde oral sebanyak $1 \mathrm{ml}$. Setiap pemberian sampel dekokta kayu bajakah dibuat segar.

\section{Persiapan Hewan Uji}

Jumlah hewan uji dihitung menggunakan rumus federer $=(\mathrm{t}-1)(\mathrm{n}-1) \geq 15, \mathrm{t}$ adalah jumlah kelompok perlakuan dan $\mathrm{n}$ adalah jumlah hewan yang dibutuhkan. Dari hasil peritungan dibutuhkan 24 ekor yang terbagi masing masing kelompok 6 hewan uji.

Hewan uji yang digunakan adalah tikus putih jantan dengan berat $200-300$ gram. Tikus di adaptasi selama satu minggu di Laboratorium dengan diberi pakan minum standar. Pengelompokkan hewan uji dilakukan secara acak, dibagi menjadi 4 kelompok diletakkan dalam kandang yang terpisah.sebelum dilakukan peerlakuan hewan uji dipuasakan selama 6 jam.

Induksi Udem dengan Karagenin

Karagenin $1 \% \quad(\mathrm{~b} / \mathrm{v})$ dibuat dengan cara mensuspensikan 1 gram karagenin dalam suspensi CMC $0,5 \%$ sampai $100 \mathrm{~mL}$. Volume karagenin yang diinjeksikan ke kaki tikus adalah 0,5 ml. indicator udem bias dilihat secara visual kaki tikus bengkak, kemerahan. Volume pembengkakan kaki tikus diukur dengan alat plethysmometer dengan mencatat kenaikan air raksa pada alat tersebut. Plethysmometer dihidupkan dan dikondisikan selama 3 menit. Plethysmometer dikalibrasi dahulu sebelum digunakan. Pengukuran dilakukan dengan cara mencelupkan kaki tikus kedalam tabung yang berisi larutan larutan pengukur sampai batas tanda berwarna merah. Pengukuran Volume udem dilakukan selang waktu 1,2,3,4,5,6 jam.

\section{Pengolahan Data}

Data yang di proleh berupa volume kaki tikus, kemudian digunakan untuk menghitung volume udem. Volume udem merupakan selisih kaki tikus sebelum dan sesudah diradangkan dengan rumus:

$\mathrm{Vu}=\mathrm{Vt}-\mathrm{Vo}$

Keterangan :

$\mathrm{Vu}$ : Volume udem kaki tikus setiap waktu

$\mathrm{Vt}$ : Volume kaki tikus setelah di radangkan dengan kragenin pada waktu $\mathrm{t}$

Vo : Volume kaki tikus sebelum diradangkan karagenin

Setelah diproleh kurva volume udem kaki tikus vs waktu, selanjutnya digunakan untuk menghitung AUC (Area under the curve) kurva antara rata-rata volume udem terhadap waktu. Rumus yang digunakan untuk menghitung AUC adalah :

$\mathrm{AUC}=\frac{V t n-1+V t}{2}=\left(\mathrm{t}_{\mathrm{n}}-\mathrm{t}_{\mathrm{n}-1}\right)$

Keterangan :

AUC : Luas daerah rata-rata di bawah kurva yang merupakan hubungan tebal edema rata-rata tiap waktu (Area Under Curva)

Vtn-1 : rata-rata volume udem pada $t_{n-1}$

Vtn : rata-rata volume udem pada $t_{n}$

tn-1 : waktu pengukuran sebelumnya dari jam ke-0 sampai jam ke-6

tn : waktu pengukuran telapak kaki tikus dari jam ke-0 sampai jam ke-6

Persentase daya antiinflamasi (penghambat volume udem) dihitung berdasarkan harga AUC kontrol negatif dan harga AUC kontrol perlakuan pada tiap individu menggunakan rumus berikut :

$\% D A I=\frac{\text { AUC } \mathrm{k}-\mathrm{AUC} \mathrm{p}}{\mathrm{AUC} \mathrm{k}} \times 100 \%$

Keterangan :

$\%$ DAI : persen daya antiinflamasi

AUCk : AUC rata-rata volume udem terhadap waktu untuk kontrol negatif

AUCp : AUC rata-rata volume udem terhadap waktu untuk kelompok perlakuan pada tiap individu (Notoadmojo, 2010) 


\section{Hasil dan Pembahasan}

Hasil pembuatan dekokta kayu Bajakah

Dekokta kayu bajakah tampala yang dihasilkan memiliki ciri organoleptis sebagai berikut :

a. Warna : merah

b. Aroma : khas seperti teh

c. Rasa : pahit

Hasil skrining fitokimia senyawa falvonoid

Untuk memastikan kandungan Flavonoid dilakukan uji kualitatif dengan hasil sebagai berikut:

Tabel 1.1 Hasil skrining fitokimia senyawa flavonoid

\begin{tabular}{|c|c|c|c|}
\hline No. & Uji & Hasil & Ket \\
\hline 1 & Flavonoid & Warna Jingga & + \\
\hline
\end{tabular}

Dekokta bajakah tampala positif mengandung senyawa flavonoid di tandai dengan terbentuknya larutan warna jingga.

\section{Hasil pengukuran Volume Udem}

Hasil pengukuran volume udem pada kaki tikus pada semua kelompok perlakuan adalah sebagai berikut:

Tabel 1.2 Distribusi Data Udem Rata-rata Hewan Uji pada setiap kelompok perlakuan

\begin{tabular}{|c|c|c|c|c|c|c|c|}
\hline \multirow{2}{*}{ Kelompok } & \multicolumn{7}{|c|}{ Volume udem (mL) pada jam ke- } \\
\cline { 2 - 8 } & $\mathbf{0}$ & $\mathbf{1}$ & $\mathbf{2}$ & $\mathbf{3}$ & $\mathbf{4}$ & $\mathbf{5}$ & $\mathbf{6}$ \\
\hline $\begin{array}{c}\text { Kontrol } \\
\text { Negatif }\end{array}$ & 0,014 & 0,016 & 0,017 & 0,019 & 0,017 & 0,019 & 0,020 \\
\hline Kontrol positif & 0,014 & 0,008 & 0,006 & 0,004 & 0,0026 & 0,0003 & 0 \\
\hline Perlakuan 1 & 0,012 & 0,009 & 0,007 & 0,0046 & 0,003 & 0,001 & 0 \\
\hline Perlakuan 2 & 0,012 & 0,013 & 0,009 & 0,007 & 0,0056 & 0,0036 & 0,0023 \\
\hline
\end{tabular}

Hasil perhitungan Persen Daya antiinflamasi .

Sebelum dilakukan perhitungan terlebih dahulu kita hitung Area Under Curve (AUC) dari data volume udem. Hasil perhitungan sebagai berikut:

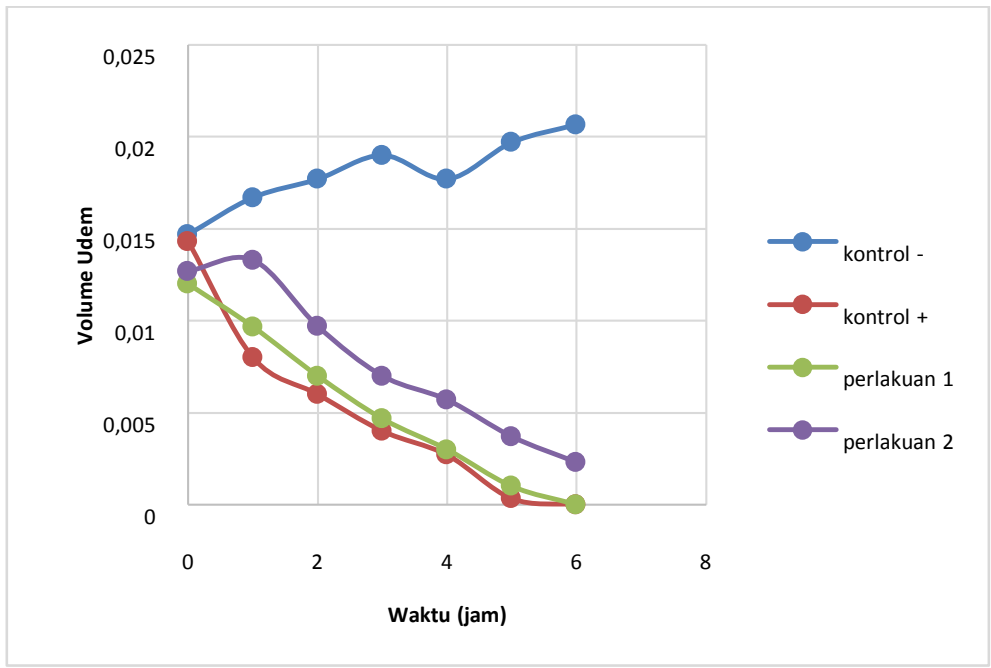

Gambar 1 Grafik AUC Volume udem rata-rata 
Tabel 1.3 Data perhitungan AUC (Area Under Curve) Uji Antiinflamasi Dekokta Kayu Bajakah dan persen Daya Anti Inflamasi (\%DAI)

\begin{tabular}{|c|c|c|}
\hline Kelompok & AUC & $\begin{array}{c}\text { \% Daya Anti } \\
\text { Inflamasi }\end{array}$ \\
\hline Kontrol Negatif & 0,10833 & - \\
\hline Kontrol positif & 0,02816 & 74,00 \\
\hline Perlakuan 1 & 0,03133 & 71,08 \\
\hline Perlakuan 2 & 0,04683 & 56,77 \\
\hline
\end{tabular}

Keterangan:

Kontrol negatif : Kelompok perlakuan pemberian inductor karagenin dan Na-CMC per oral

Kontrol positif : Kelompok perlakuan pemberian inductor karagenin dan Natrium diklofenak

Perlakuan 1 : Kelompok perlakuan yang diberi dekokta kayu bajakah dosis 20g/100 ml selama 3 hari sebelum pengujian diberikan dekokta kayu bajakah $2 \times$ sehari, kemudian pada hari pengujian diberikan dekokta kayu bajakah dan diinduksi karagenin $1 \%$

Perlakuan 2 : Kelompok perlakuan diberi dekokta kayu bajakah volume pemberian $1 \mathrm{ml} / 200$ gram berat tikus kemudian diinduksi karagenin $1 \%$

Pada tabel diatas kelompok kontrol positif memiliki persen Daya Anti Inflamasi yang paling tinggi sebesar 74,04\%, selanjutnya perlakuan 1 sebesar 71,08\%, dan terakhir adalah perlakuan 2 sebesar 56,77\%.

Hasil uji statistic adalah sebagai berikut: dimulai dari uji homogenitas data dan distribusi normal

Tabel 1.4 Hasil uji SPSS homogenitas dan distribusi data volume udem kaki tikus

\begin{tabular}{|l|l|l|l|}
\hline No. & Uji Statistika & Hasil & Keterangan \\
\hline 1. & Normalitas Saphiro-Wilk & Kontrol Negatif 0,430 & Terdistribusi normal \\
& & Kontrol positif 0,743 & Terdistribusi normal \\
& & Perlakuan 1 0,156 & Terdistribusi normal \\
& & Perlakuan 2 0,022 & Tidak Terdistribusi normal \\
\hline 2. & Homogenitas & 0,127 & Data homogeny \\
\hline
\end{tabular}

Dari data tersebut dilanjutkan uji kruskal walis dengan hasil sebagai berikut:

Tabel 1.5 Hasil Uji Non-Parametric Kruskall-Wallis

\begin{tabular}{|c|l|c|c|}
\hline \multicolumn{2}{|c|}{ Perlakuan } & N & $\begin{array}{c}\text { Mean } \\
\text { Rank }\end{array}$ \\
\hline AUC & kontrol negatif & 6 & 21.50 \\
& kontrol positif & 6 & 5.50 \\
& perlakuan 1 & 6 & 8.00 \\
& perlakuan 2 & 6 & 15.00 \\
& Total & 24 & \\
\hline
\end{tabular}

\begin{tabular}{|c|c|}
\hline \multicolumn{2}{|c|}{ Test Statitics } \\
\hline & AUC \\
\hline Chi-Square & 18.903 \\
df & 3 \\
Asymp. Sig. & .000 \\
\hline
\end{tabular}

a. Kruskal Walis Test

b. Grouping Variable : perlakuan

Hasil uji Kruskall-Wallis menghasilkan signifikansi 0,000 yang artinya lebih kecil dari 0,05 maka artinya pada setiap antar perlakuan terdapat perbedaan secara bermakna. Oleh karena itu selanjutnya dilakukan uji MannWhitney. 
Tabel 1.6 Hasil Uji Mann-Whitney

\begin{tabular}{|c|c|c|}
\hline Kelompok & Signifikansi & Keterangan \\
\hline Negatif vs positif & 0,002 & $<0,05$ maka berbeda bermakna \\
\hline Negatif vs perlakuan 1 & 0,002 & $<0,05$ maka berbeda bermakna \\
\hline Negatif vs perlakuan 2 & 0,002 & $<0,05$ maka berbeda bermakna \\
\hline Positif vs perlakuan 1 & 0,394 & $>0,05$ maka tidak berbeda bermakna \\
\hline Positif vs perlakuan 2 & 0,002 & $<0,05$ maka berbeda bermakna \\
\hline Perlakuan 1 vs perlakuan 2 & 0,015 & $<0,05$ maka berbeda bermakna \\
\hline
\end{tabular}

Hasil uji Mann-Whitney menunjukkan bahwa hanya kontrol positif dan perlakuan 1 yang tidak terjadi perbedaan secara bermakna atau hasil penurunan volume udem tidak berbeda secara bermakna.

\section{Pembahasan}

Kayu Bajakah yang dibuat sediaan dekokta memiliki kandungan flavonoid yang merupakan metabolit sekunder pada tanaman sesuai dengan hasil penelitian maulina 2019. Kandungan tersebut dapat dimanfaatkan untuk manusia sebagai obat herbal untuk pengobatan berbagai penyakit yaitu kanker (Putra, 2019), penyembuhan luka (Saputra, 2018), antibakteri (Saputra , 2019). Terbukti dari hasil penelitian menunjukkan kemampuan dekokta kayu bajakah mampu menurunkan Volume udem pada kaki tikus yang diinjeksi karagenin. Karagenin memiliki efek merusak jaringan sekitar tempat pemberian yaitu di kaki tikus yang teramati dengan cirri kaki meradang/ bengkak dan kemerahan. Karagenin meninduksi terbentuknya prostaglandin yaitu meditor nyeri dan inflamasi yang siffatnya sementara (Hidayati, 2008).

Dari hasil penelitian menunjukkan kelompok control positif menghasilkan daya anntiinflamasi yang paling tinggi karena pemebrian natrium diklofenak yang memiliki efek antiinflamasi dengan mekanisme menghambat prostaglandine yang diinduksi dari karagenin mampu menurunkan volume udem secara signifikan. Sebagai pembanding control negatif digunkan $\mathrm{CmC}$ karena larutan $\mathrm{cmc}$ juga digunakan untuk melarutkan natrium diklofenac. Pada control negative udem bertahan sampai jam ke 6 pengamatan. Selama 6 jam volume udem masih stabil tetapi pada control positif terjadi penurunan ini membuktikan bahwa cmc pada penelitian ini tidak memiliki efek menurinkan udem.

Perlakuan 1 yaitu kelompok yang diberikan tiga hari berturut turrt dekokta kayu bajakah menunjuukkan hasil yang tidak jauh berbeda dengan control positif hal ini disebabkan karena kadar Flavonoid dalam darah lebih tinggi dan stabil dibandingkan dengan perlakuan 2 yang hanya diberikan dekokta kayu bajakah satu hari dengan volume pemberian $1 \mathrm{ml}$. hasil ini dipertegas dengan hasil olah data statistic yaitu dari uji mann whitney diperoelah nilai signifikansi perlakuan 1 dan control positif berbeda tidak bermakna.

\section{Kesimpulan}

Dekokta Kayu Bajakah mampu menurunkan udem pada kaki tikus yang diinduksi karagenin sama dengan natrium diklofenak dengan nilai signifikansi 0,394

\section{Daftar Pustaka}

Anshari, M. I. (2012). Isolasi dan Identifikasi Senyawa Kimia Fraksi Etil Asetat Batang Bajakah Tampala (Lambung Mangkurat). Retrieved from http://opac.lib.unlam.ac.id/id/opac/detail.php ?q1 $=546 \& q 2=$ Ans \&q3 $=\mathrm{i} \& \mathrm{q} 4$

Balitbang Kemenkes. 2019. Penelitian Bajakah untuk Obat Kanker Masih Sangat Awal. https://www.liputan6.com/health/read/40390 91 /balitbang-kemenkes-penelitianbajakahuntuk-obat-kanker-masih-sangatawal.

Bramasta, D.B. dan Sartika, R.E.A. 2019. Bukan Hanya Manusia, Orangutan Pun Merasakan Manfaat Bajakah, Kompas.com,

Fitriani, A.2019. Fenomena Kayu Bajakah dalam Kajian hukum Perlindungan Konsumen dan Hukum Islam

Fitriya. 2019. 12 Fakta Obat Kanker Akar Bajakah, Sayang Kalau Dilewatkan, https://www.cermati.com/artikel/12-faktaobat-kanker-akar-bajakah-sayangkalaudilewatkan.

Hidayati, N.A., Listyawati, S., dan Setyawan, A.D. (2008). Kandungan kimia dan uji antiinflamasi ekstrak etanol Lantana cemara L. pada tikus putih (Rattus norvegicus L.) jantan. Bioteknologi, 14.

Ilavarasan R, Malika, M., and Venkataraman, S.2005. Antiinflammatory and Antioxsidant Activies of Cassia fistula Bark Extracts, Afr, J. Traditional. CAM 2(1) : 70-85

Ma'As, Alvin Saputra, 2012. JENIS-jenis-pelarutkimia,http://id.scribd.com/doc/25340903/

Maulina, S., Pratiwi, D. R., \& Erwin, E. (2019). Skrining Fitokimia dan Bioaktivitas Ekstrak Akar Uncaria nervosa Elmer (Bajakah). Jurnal Atomik, 4(2), 100-101 
Raharni, dkk,2009. Uji anti inflamasi jambu mete (Ancacardium occidentale L). Skripsi jakarta Badan Litbang Kesehatan.

Saputera, M. M. A., \& Ayuchecaria, N. (2018). Uji Efektivitas Ekstrak Etanolik Batang Bajakah Tampala (Spatholobus Littoralis Hassk.) Terhadap Waktu Penyembuhan Luka. Jurnal Ilmiah Ibnu Sina, 3(2), 318-327.

Saputera, Mochammad Maulidie Alfiannor, Mapaung, T. W. A., \& Ayuchecaria, N. 2019. Konsentrasi Hambat Minimum (KHM) Kadar Ekstrak Etanol Batang Bajakah Tampala LA (Spatholobus littoralis Hassk) Terhadap Bakteri Escherichia Coli Melalui Metode Sumuran.Jurnal Ilmiah Manuntung,5(2), 167-173.

Yusuf Dwi Putra, 2019, “Ternyata Jenis Tumbuhan

Bajakah Berikut Ini yang Dapat Menyembuhkan Kanker", https://blogs.insanmedika.co.id/akarbajakah/ (Online 07 September 2019) 